SALINITY DISTRIBUTION AND EFFECT OF FRESH WATER FLOWS IN THE HOOGHLY RIVER

\author{
U. V. Gole \\ Director \\ $\&$ \\ P.P.Vaidyaraman \\ Chief Research officer
}

Central Water \& Power Research Station,Poona, India.

\title{
ABSTRACT
}

An examination of the hydraulic characteristics of the ifooghly river with particular reference to the pattern of salinity intrusion and the effects of fresh water flows has been made in this contribution. It is seen that the conditions prevailing are such that during the brief period of fresh water flows the problem of salinity intrusion is absent. The beneflcial effect of fresh water flows in improving the navigable depths along the river is also shown. The cessation of fresh water flows causes the deterioration of navigable depths due to the lendward movement of sediment; it also results in the upstream encroachment of salinity affecting the supply of drinking water to the city of calcutta. It has also been shown that even during the period in the freshet when the salinity profiles exist the estuary remains well-mixed. The need for augmentation of fresh water flows for improving the conditions has also been brousht out. A few remarks on the comparative features of Yooghly and other tidal rivers have also been added to spotlieht on the vastly different characteristics of the Hooghly.

1. INTRODUCTIUN

The port of calcutta located about $100 \mathrm{~N}$.miles inland from the sea on the river Hooshly (Lat.220 32, $53^{n}$ N.Long.88 18' 05" East) has steadily developed since it was founded by Job charnock in 1690 and is one of India's most important Ports to-day. (Fig.1). With an annual tonnage handled being over $11 \mathrm{~m}$.tons, the port's primary exports are - coal, Tea, Jute, Manganese ore, Pig Iron etc. While the chief imports are - Petrolium, Foodgrains, Machinery etc. In view of the importance of the port, the navigability along the river has been $a$ subject of detailed consideration since some time.

\section{HOCGHIY RIVER}

The Eooghly river is formed by the confluence of three rivers, generally referred to as Nadia rivers, viz, the Bhagirathi, Jalangi and Mathabhanga-Churni, of which the 
Bhagirathi which takes of f from the river Ganges at Biswanathpur, is the most important since it is the main channel bringing fresh water discharge into the Hooghly. The Hooghly river is subject to varying tidal action due to the tides emanating from the Bay of Bengal, (maximum range at the mouth $17 \mathrm{ft}$.$) . The tidal limit ext ends to swarupgunj about 76 \mathrm{~N}$. miles upstream of calcut ta in the dry season but is pushed down during the period of fresh water flows. The tidal currents exhibit seasonal variation in their strength and attain their maximum during the period when there is no fresh water flows.

A notable feature in the Hooghly is the formation of 'bore-tides' characterised by a sudden and almost vertical rise of water level immediately after low water. 'Bores'now occur practically on every spring tide. The maximum 'bore' height is of the order of $8 \mathrm{ft}$, and speed of travel about 18 to 20 miles per hour.

The channel geometry is very irregular as evident from the variation of areas and widths along the river. This is primarily due to the existence of numerous curves and bends and sudden divergence of sections. The existence of these curtes and bends gives rise to the divergence of ' flood and ebb axes with the result the crossing from one bank to the other remains shallow, necessitating dredging for the required navigable depths to be maintained. Along the river sereral such bars/crossings exist from calcutta right up to the sea and the important ones are - Panchpara, Sankrail-Munikhali, Pirserang, Poojali, Moyapur, Royapur, Ninan-Nurpur, Easterm Gut, Balari (Fig.2). As the strength of the chain lies in its weakest link, the minimum depth over these bars governs the permissible draft and hence the movernent of ships.

Upland Fresh Water Flows - The Hooghly receives its major share of fresh water flows from the Ganges through the Bhagirathi. Owing to the high level of the off-take the spili from the Ganges to the Bhagirathi occurs only during the period when the levels in Ganges are fairly high. Figure 3 shows the hydrographs at Kalna for the period 1962-65 (23 N.miles downstream of Swarupgunj). It is apparent that significant fresh water flows occur only durins the period July to october. Barring abnormal flows the normal maximum flow is of the order of $1,20,000 \mathrm{cfs}$. It is of interest to note that the hydrographs exhibit rapid rise and fall, which are important in regard to the distribution of salinity and also the navigable depths al ons the river. considerable sediment load is brought down by the fresh water flows, estimated to be of the order of $50 \mathrm{~m}$.cu.yds. It is the pattern 
of movement of this sediment that governs the navigable depth along the river.

\section{SALINITY DISTRIBUTION}

The importance of salinity in estuarine environments has been recognized since quite sometime in view of the possibility of the problems of sedimentation in navigable waterways being interlinked with the patterm of salinity variation and the resulting distribution of current velocities. Depending upon the degree of mixing between the fresil and saline waters, an estuary may vary from a well-mizea type to a stratified type, the former indicating the predominance of tidal forces over the fresh water flows and the latter the other extreme case of minimum mixing and maximum variation in the salinity distribution over the vertical arising due to weak tidal action and large fresh water flows. Where mixing is not of a high order, the density currents set up alonE the bottom of the channel would tend to transport the material along the bed upstream causing formation of a shoal near about the limit of 'intrusion'. It is, therefore, generally appreciated that studies relating to the improvement of waterways should consider the effects on salinity distribution to aroid any such illeffects.

As in the case of other tidal rivers, the Hooghly also exhibits its own characteristic salinity distribution along its length. Apparently the inflow of fresh water from upstream is intimately connected with the pattern of salinity distribution along the river.

With the onset of fresh water flows, the salinity decreases from the upper reaches, this effect progressively travelling downwards with the increase in the fresh water flows. By the time the discharge is about $40,000 \mathrm{cfs}$. the salinity limit is pushed down below calcutta and the effect of the further rapid rise in discharge is such that even at Balari where the dry season salinity is of the order of 30 PPT the water is rendered practically sweet. The rate of rise of the inflow hydrograph goverms the time by which Balari waters become sweet. And since the discharge continues at this high level, despite the fluctuations in the hydrograph, no encroachment of salinity occurs. Even at Auckland bar, $13 \mathrm{~km}$ below saugor the salinities are substantially reduced during freshets, as can be seen from the values given below - 


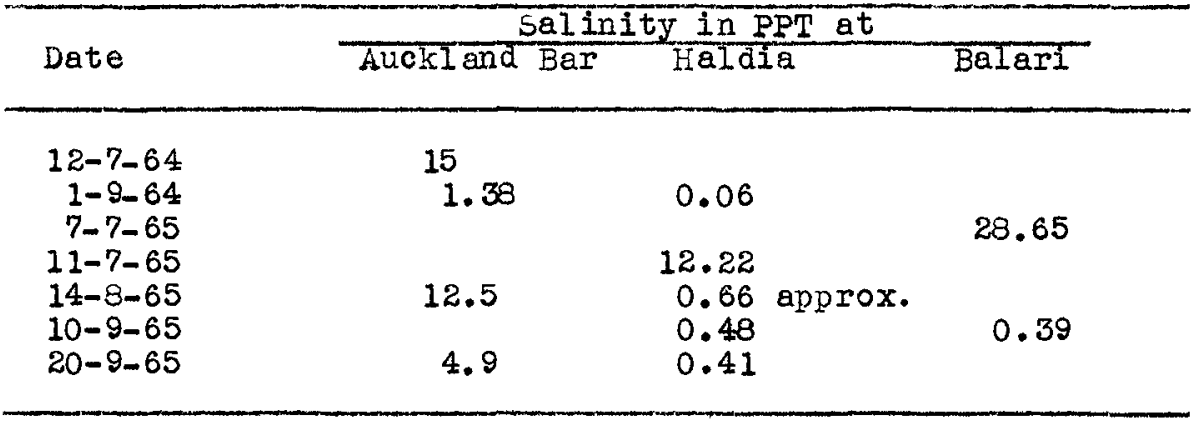

By the end of september the hydrograph shows a falling trend and by November the flows are very small. However, the impounded fresh waters have the beneficial effect of ariesting a sudden encroachment of salinity as soon as the discharge falls down. Thus in December the salinity at Faldia is of the order of 4 PPT whereas at the upper stations, Moyapur and Garden Reach, the salinities are well below potable limit. The salinity gradually increases first at Moyapur by the end of December and at Garden Reach the effect is felt only by the beginning of February, this lag again depending upon the fresh water flows during the earlier period. over the period July to october when the freshet flow exists the looghly river over its main problem zone remains sweet and rree from any salinity effect. Figure 4 shows the salinities at different stations for the perlod october to August.

The salinity encroaches into the upstream reacies gradually after the fresh water thow ceases and the tidal forces gain in strength. In the absence of fresh water flows the intmaion takes place in a homogeneous fashion. The formation of 'bores' in the dry season also helps in creating additional turbulence which helps to effect a thorough mixing of the water contents in the river. The maximum salinities at calcutta are of the order of 8 PPT.

The encroachment of salinity into the upper reaches in the dry season poses a problem of direct concern since this afrects the supply of water to the calcutta city. Water supply for drinking purposes to the city are drawn from the Fooghly through the water works at $P a l t a$, about 18 miles north of calcutta. Originally when the water works were established in 1867 it was possible to supply sweet water from the river round the year but of late due to the deterioration of the channel capacities and the upstream encroachment of salinity, supply of sweet water during the dry weather period, say March to June, is becoming a serious problen. It has become essential to arrest this intrusion by 
suitable measures and restore the water supply position.

It can thus be seen that the salinity distribution along the Hooghly in the dry season is vastly different from that in the freshet season unlike many other tidal rivers.

Though the river waters have some salinity only for a brief period of about a montin, after the freshets begin, after which the increase in discharge pushes the salinity limit down to below Maldia, it will be interesting to make an assessment of the mixing characteristics in the zone of salinity intrusion in this transition period.

of the approaches postulated by Schultz \& Simons, Abbot (2) and Ippen \& Hariemen $(3,4)$ the application of the method indicated by $\mathrm{M} / \mathrm{s}$ Ippen \& Harleman is made herein. The method essentially consists of assessing the ratio, of the rate of dissipation of turbulent energy per unit mass of fluid to the rate of gain of potential energy per unit mass of the fresh water flow in its travel through the saline zone, termed the stratification parameter $(G / J)$. G, the rate of dissipation of energy per unit mass is obtained from analysis of prototype tidal data. J, the rate of gain of potential energy per unit mass is obtained by considering that the net flow over any section is only due to fresh water discharge and ascertaining the average increase in density in the intrusion zone from known salinity distribution, and is given by the formula -

$$
J=\frac{\gamma_{x}-\gamma_{f}}{\gamma_{i}} \operatorname{gh} \nabla_{f} / \mathrm{L}
$$

where $V_{f}$ is the fresh water velocity,

$Y_{X}=$ density at any section $x$,

$\gamma_{\mathbf{f}}=$ fresh water density,

$\mathrm{h}=$ mean depth

$L=1$ ength of intrusion.

Large value of this ratio is indicative of well-mixed conditions. It has been suggested that values of the order of 2000 are indicative of a very high degree of mixing.

The basic data used and the results of computation are given in Table $I$.

These show that the values are large (2000 or near about) representing highly mixed conditions. This is also borne out from the available data of salinity and velocity distribution over the vertical at different stations which show no trend for reversal.(Fig.5) In order to obtain the 
critical value of this stratification parameter below which stratified conditions would exist, for practical purposes, it would be necessary to extend the computations over the various combinations of tidal ranges and upland discharges.

In the dry season due to the significant lack of upland discharge the values of $\mathrm{G} / \mathrm{J}$ would be automatically very high implying highly mixed conditions in the estuary, which is obvious.

\section{SHOAIING ALONG THE RIVER}

As briefly mentioned in para 2 , the peculiar geometry of the river is mainly responsible for the patterm of shoaling taking place. The existence of bends/curves results in the divergence of the flood and ebb axes. This divergence also varies due to seasonal changes in the ebb and flood currents so that the extent of the bar along the crossing \& the navigable depths over this naturally exhibit large seasonal variation. The navigable depths over two typical bars/ crossings are shown in figure 6 which depict the conditions adequately. With the onset of the freshet the channels tend to improve due to the increased ebb preponderance after an initial period of readjustment, so that beyond August depths improve considerably till the situation is offset in the dry weather period with the gain of tidal strength when the distribution of material takes place in the landward direction. During the freshets the flood cul-de-sac shifts dow and the head of the sands build up; the situation reverses in the dry season. Figure 7 illustrates this condition very well.

A typical example of the shoaling occurring in the Hooghly is obtained by the study of the conditions at sankral reach about $8 \mathrm{~N} . \mathrm{mil}$ es below calcutta. The situation of Sankrail reach spotlights the effects of the divergence of the flood and ebb axes. Below and above Akra the river sections are narrow (width 2700 ft.app rox.) but inbetween the river width is excessively large (width $4750 \mathrm{ft}$. ) due to the progressive erosion of the Akra bank by the flood flow (Fig.8). The widening of the river was accompanied by the formation of Sankrail sand extending from Hancman's Point to Wunikhali crossing. This formation gave rise to the divergence of channels for the flood and ebb currents; the ebb following tne deep channel at sankrail while the flood runs along the opposite Akra bank over the sand. During the freshets, due to the ebb preponderance the channel at sankrail bight and Iunikhali crossing improves but the flood preponderance during the dry season results in the flood cul-de-sac extending through the sankrail sand to the detriment of the naviGation channel. Both Sankrail and Munikhali crossing carry 
reduced depths and improvement of this reach had to be done by construction of a flood repelling spur at Akra for deflecting the flood on to the sankrail bight.

The deterioration in depths at other bars are generally due to this cause, though varying in degree. Since the deterioration in depths occurs due to the large tidal preponderance it would be necessary to offset this by establishing the ebb preponderance by extending the period of fresh water flows.

The material over the bars is predominantly composed of medium/fine sand varying in mean diameter from $0.15 \mathrm{~mm}$. to about $0.1 \mathrm{~mm}$. and specific gravity of about 2.6. The percentage of clay and silt generally does not exceed $10 \%$. So that the possibility of flocculation in the problem reach does not exist.

\section{SOME ADDITIONAI REMARKS}

From the various avallable examples of tidal rivers it can be appreciated that it is hard to generalise on the hydraulic conditions since no two systems exhibit identical characteristics and as such the problem and solution would depend on the particular situation in hand. In comparison with other estuaries like Delaware, Savannah, Charleston or Thames, the Hooghly river shows markedly different characteri stics. In addition to the great tortusus length of about 186 miles, the turbulence level is also high as seen from the current velocities which reach about $10 \mathrm{ft} . / \mathrm{sec}$. The occurrence of 'bore-tides' is a feature of significance both fron the point of view of distribution of sediment and hazards to navigation. The selinity intrusion is particularly interesting in that during the period of freshet the river waters are rendered practically sweet. During the dry season the lonsitudinal salinity profile extends over a creat length so that the Gradient is much flatter compared with Delaware or Tharnes which implies that salinity effects are not significant. (Delaware $20 \mathrm{PPT} / 52$ miles, Thanes $20 \mathrm{PPT} / 30 \mathrm{miles}$, Hoothly $20 \mathrm{PPT} / 75$ miles). It is also inter esting to note that the encroachment of salinity occuring only in this season is not of the "arrested type" as in other estuaries which carry a minimum amount of fresh water flow round the year. Due to the geometry of river, in a section, generally the deep channels exhibit 'ebb preponderance' whereas the shallower regions exhibit flood preponderance,(Table II), which is very much different from the situation prevailing in estuaries influenced by density effects, where over the vertical the circulation pattern would indicate ebb preponderance along the surface and flood preponderance along the bottom. The 
navigable route from the entrance to the Port is beset with numerous obstacles and shoaling problem is not confined to a particular reach. The fresh water flows are agian characteristic in that the flows exist only for a short period unlike as in Delaware or Savannah but their importance lies in the fact that they bring in considerable benefits to the river. The large semi-diurnal variation in tidal anplitudes, further, does not give rise to any sustained pattern of hydraulic equilibrium. The suspended sediment concentration in the Hooghly river is also of a high order as compared to the other estuaries. The absence of clay is conspicuous as rar as shoaling due to flocculation is concerned. It will be interesting to note that in Savannah, charleston \& Thames flscculation is the major cause of shoaling in the river. Figures 9 to 12 show some of the hydraulic parameters of Savannah, Delaware and Hooghly compared.

\section{CONCLUSIONS}

From a study of the salinity intrusion pattem in the Hooghly river it is seen that the intrusion assumes importance only during the period when no fresh water flows are available. The upland hydrographs show that presently the river receives fresh water flows only for a short period of 4 months in a year. The fresh water flows have the beneficial effects of pushing down the salinity limit to almost the river mouth and improving the depths along the tortuous navigable route. The deterioration in channel depths and the encroachment of salinity affecting drinking water supp Iies are both the result of lack of adequate fresh water flow which have to be offset by extending the period of fresh water flows.

\section{ACKNOWLEDGEMENT}

The data required for the analysis have been drawn mainly from the hydraulic data collected by the Hydraulic study Department, Calcutta Port Commissioners and some of the reports received from this department from time to time for which grateful acknowl edgement is made. The data relating to Savannah \& Delaware rivers have been taken from the reports published by the U.S.Army Engineers, Waterways Experiment station, Vicksburg. Thanks are also due to chairman, Central Water \& Power Commission, New-Delhi for permission kindly accorded for publication of this paper. Finaliy, thanks are due to $\mathrm{M} / \mathrm{s}$ G.Puttaramaiah \& S.P. Athalye for the various computations made by them and help in the preparation of figures. 


\section{REFERENCES}

1. Schultz, E.A. and simmons, H.B. (1957) Fresh Water-salt water Density Currents - A Najor Cause oí Siltation in Estuaries; Tech.Bulletin No.2, Committee on Ti dal Hydraulics, U.S.Arny Corps of Engineers.

2. Abbot, H.R.(1960) Salinity Effects in Estuaries; Journal of Marine Research, Vol.18, No.2.

3. Ippen, A.T. and Harleman, D.R.F.(1961) one Dimensional Analysis of salinity Intrusion in Estuaries; Tech.Bulletin No.5, Committee on Tidal Hydraulics, U.S.Army Corps of Engineers.

4. Harleman, D.R.F. et al (1961) An analysis of one dimensional convective diffusion phenomena in an idealised estuary; Tech.Report No.42, Hydrodynamics Laboratory, M.I.T. 


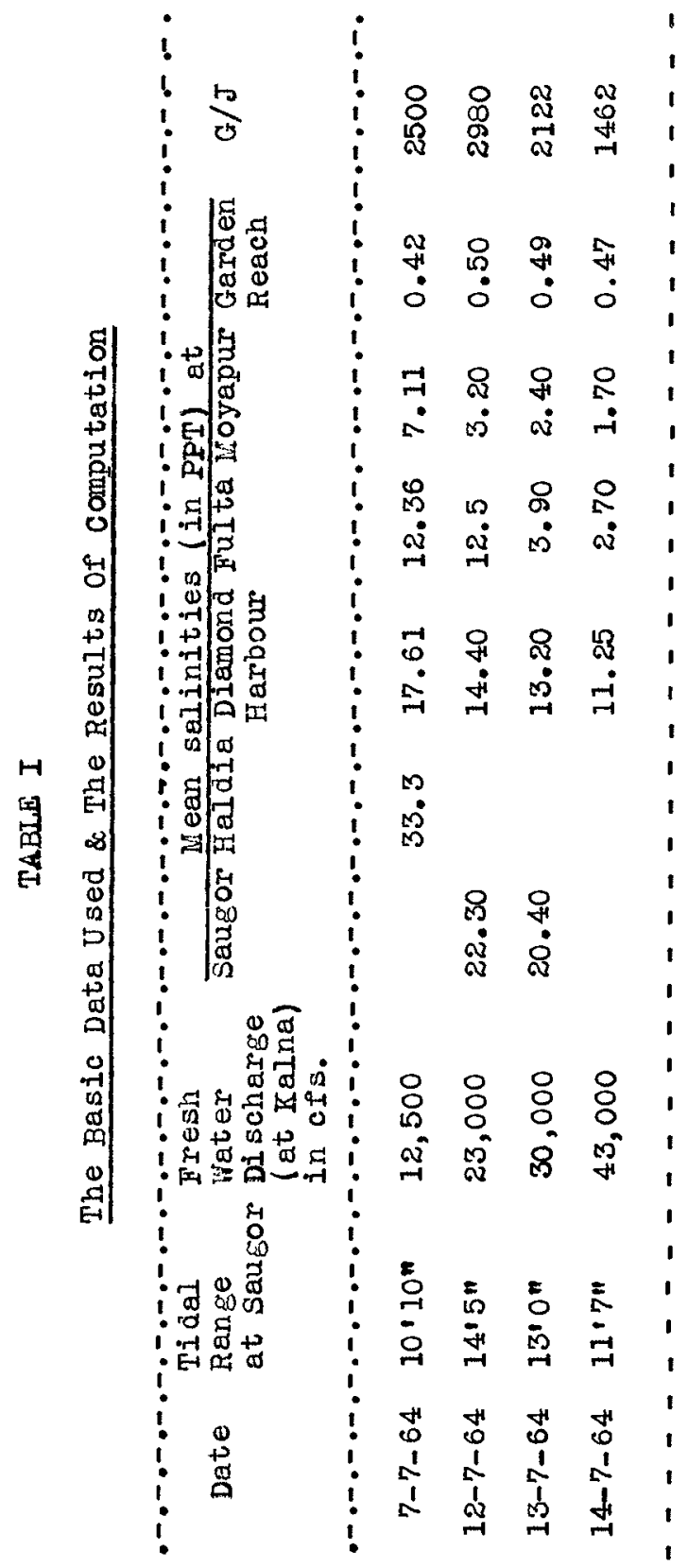


TABLE II

PERCEN TAGE EBB PREDOMINANCE (ACROSSA SECTION)

AT DIFFERENT STATIONSALONG RIVER HOOGHLY.

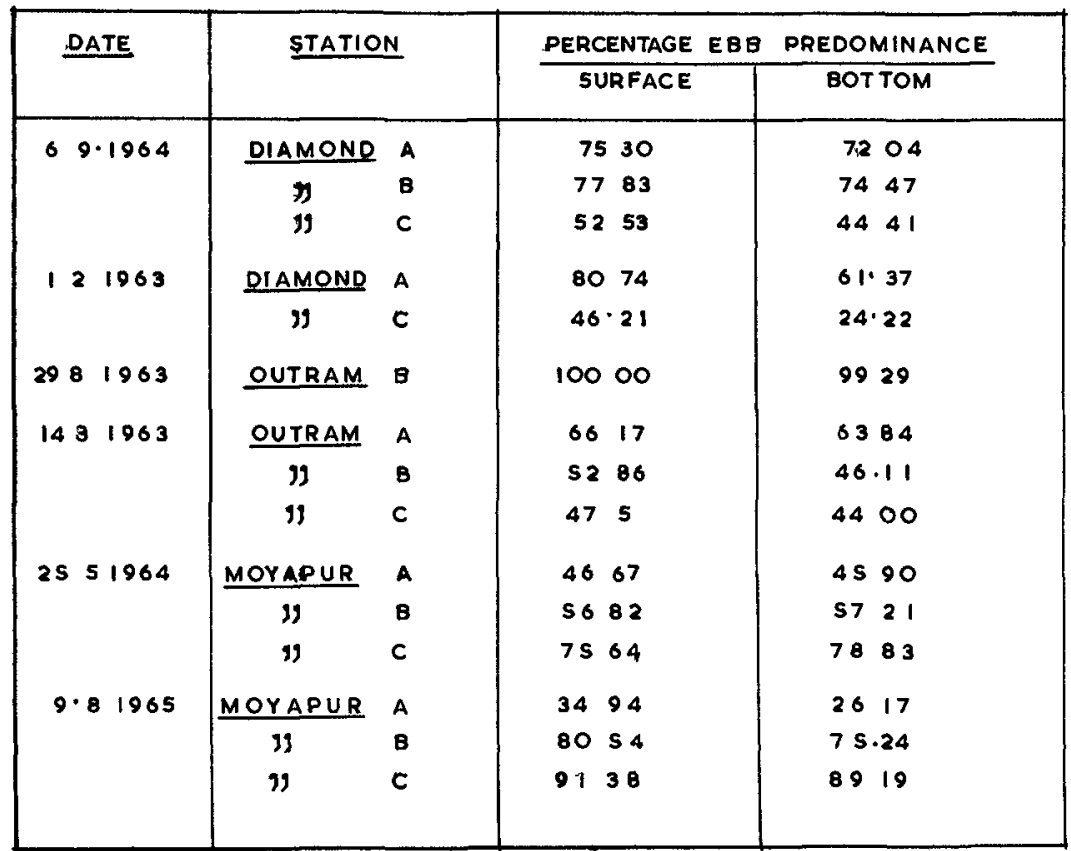

KEY PLANS

SHOWING POINTS OF OBSERVATION

DIAMOND REACH OUTRAM GHAT MOYAPUR

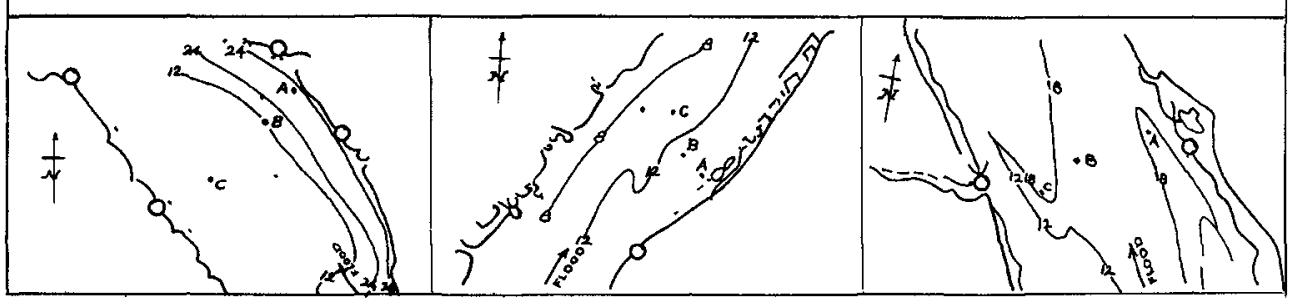




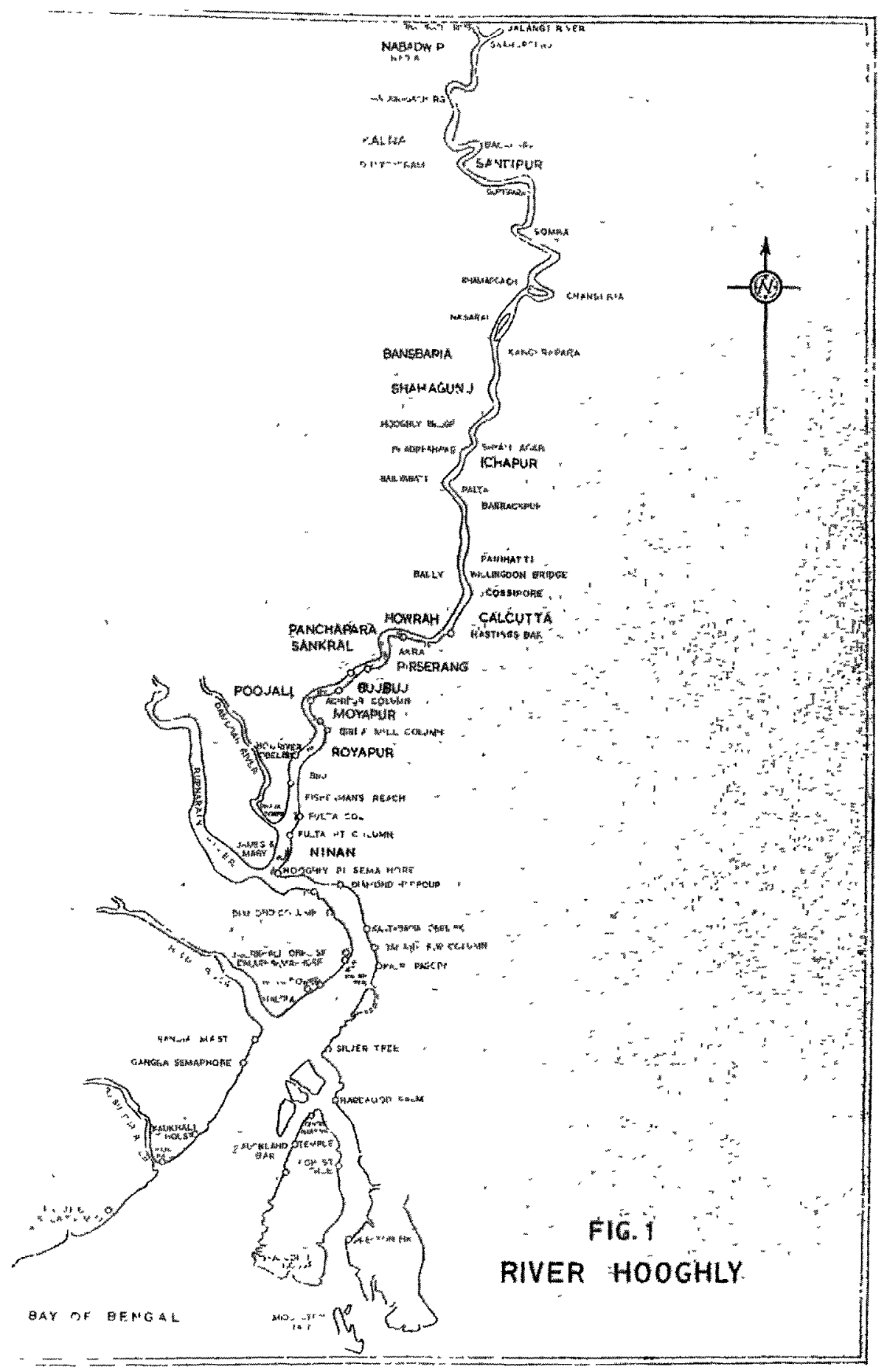




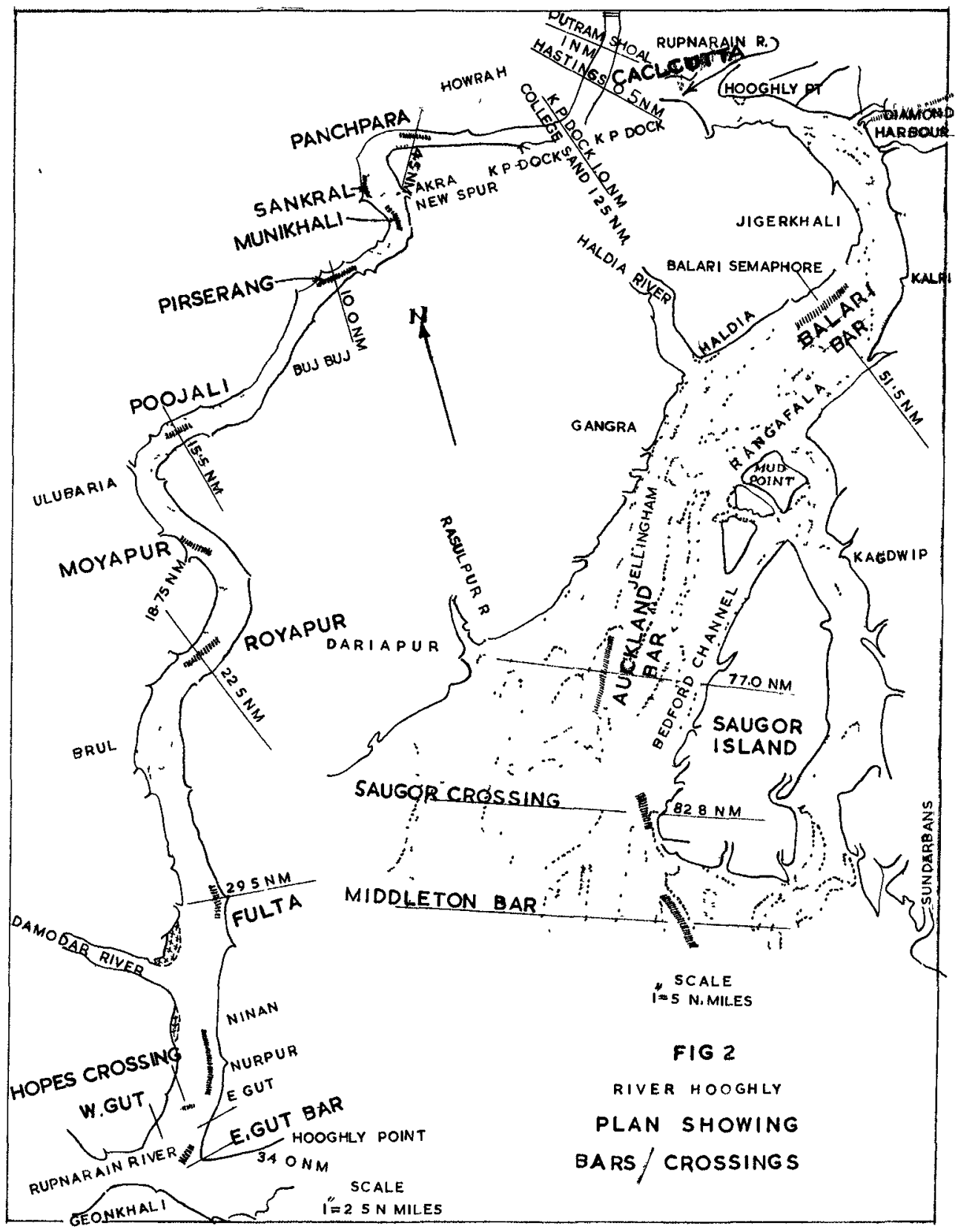




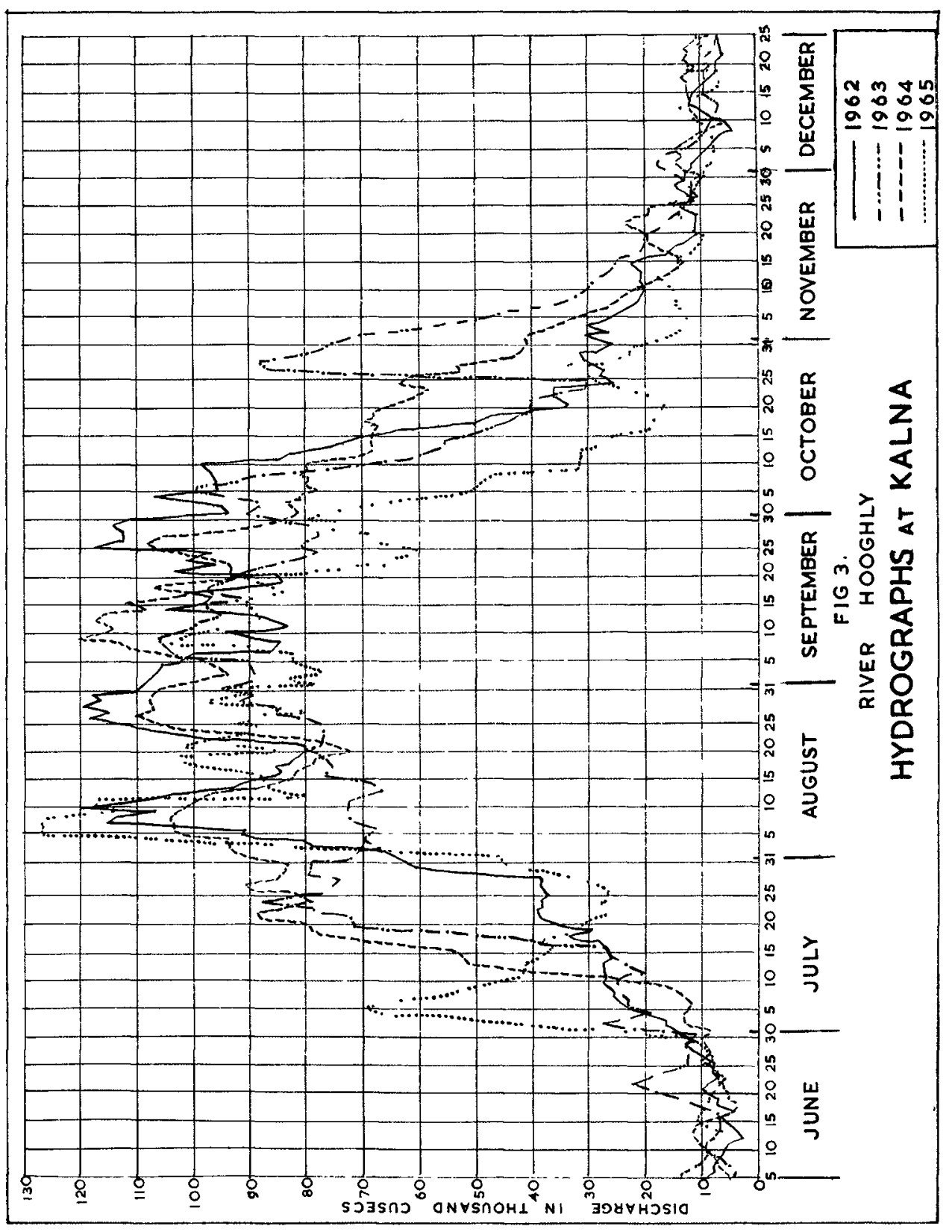




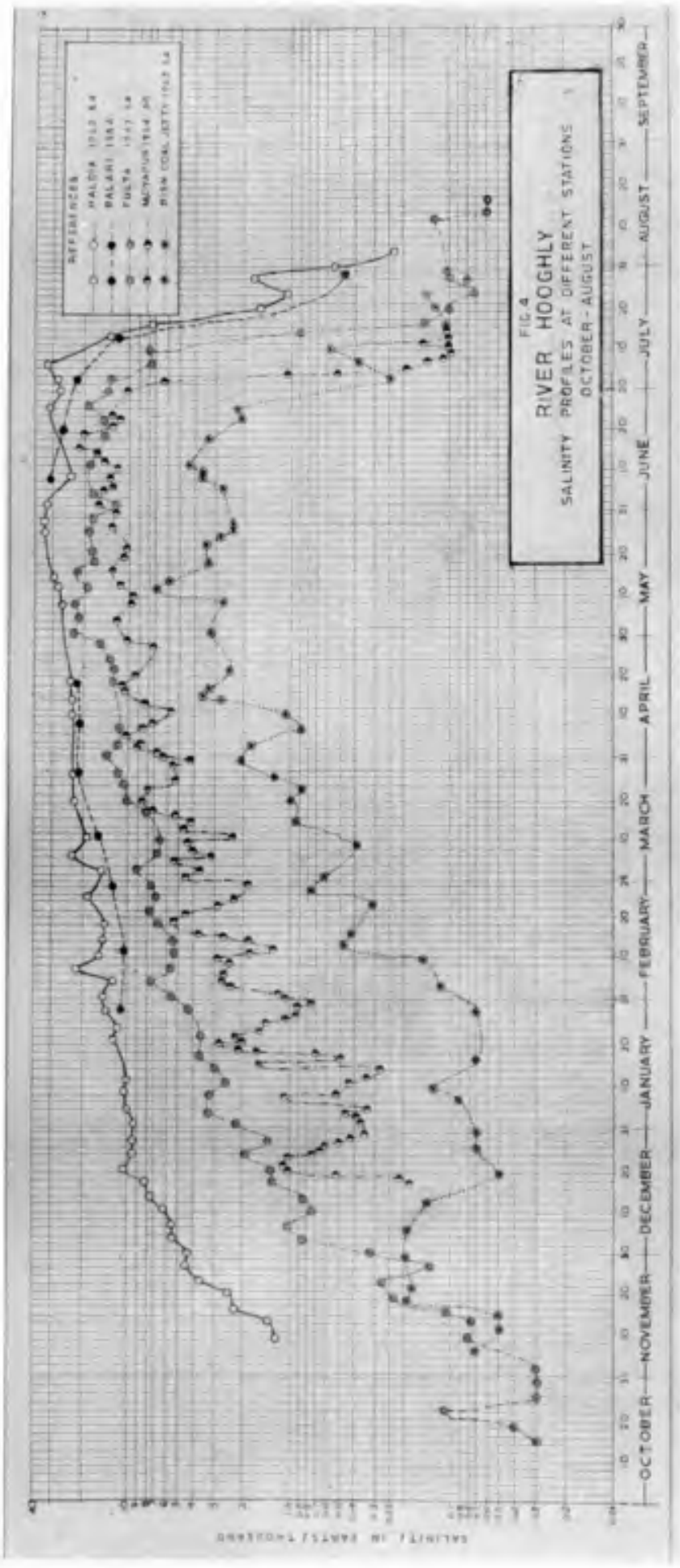




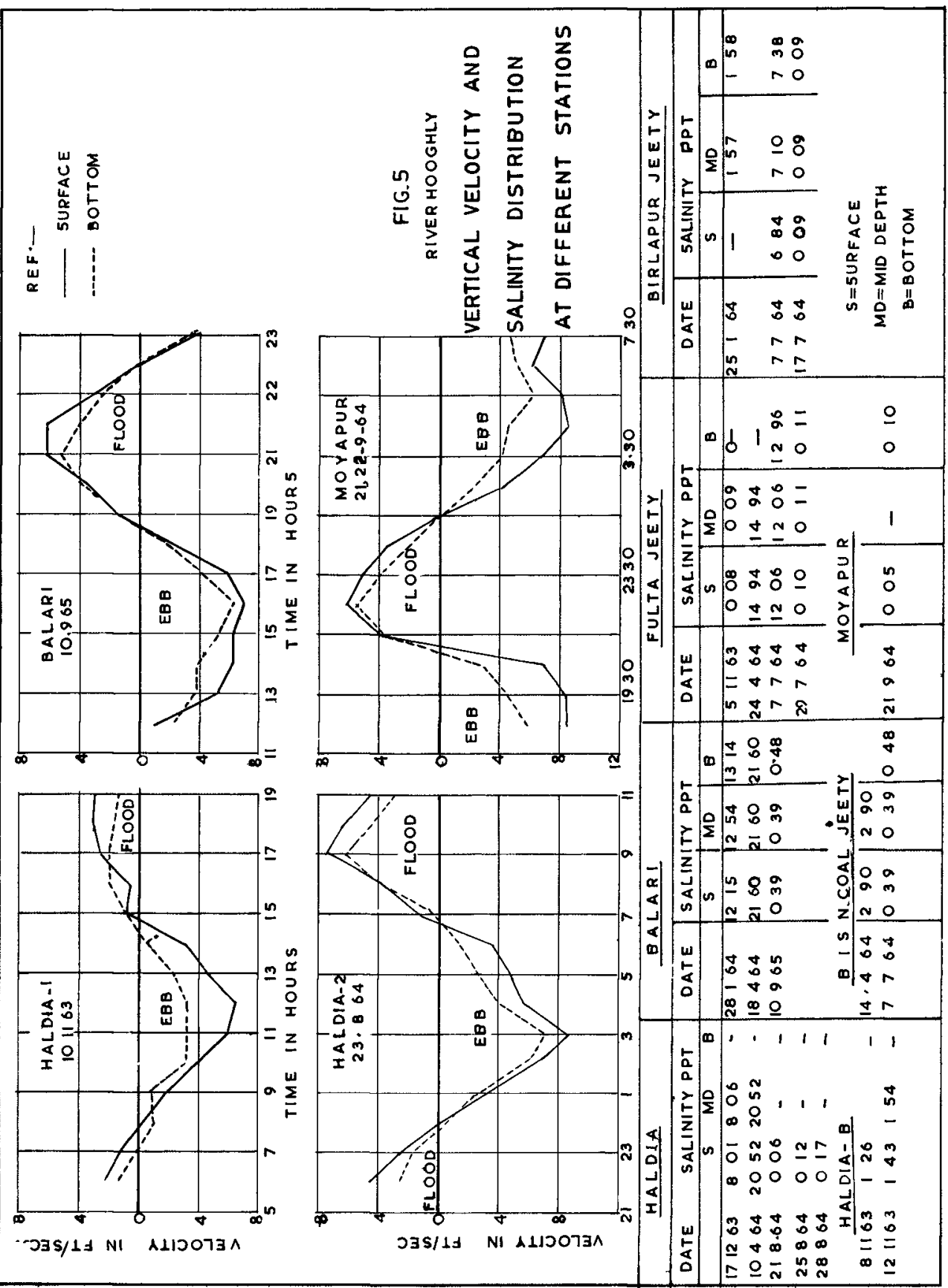




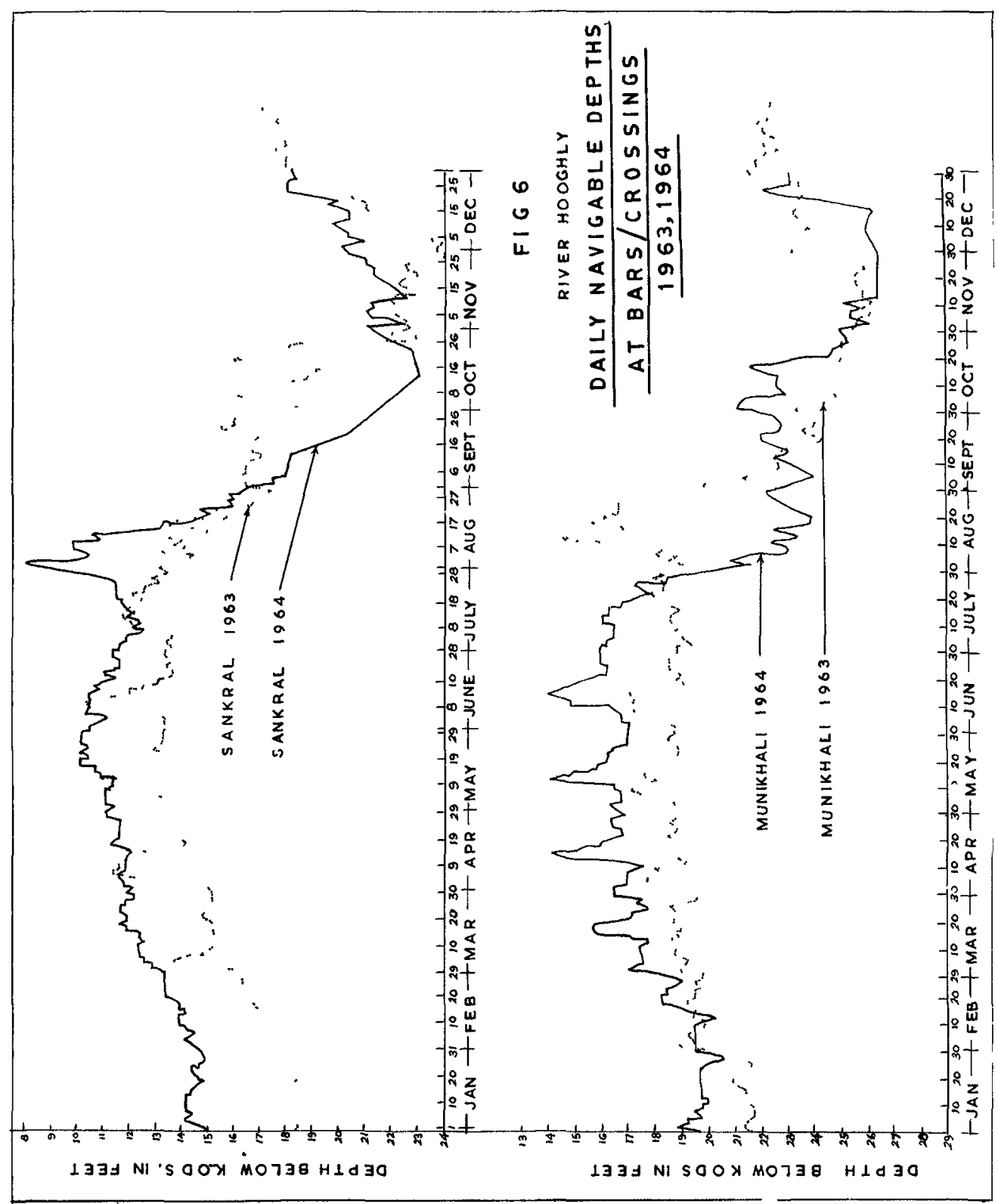




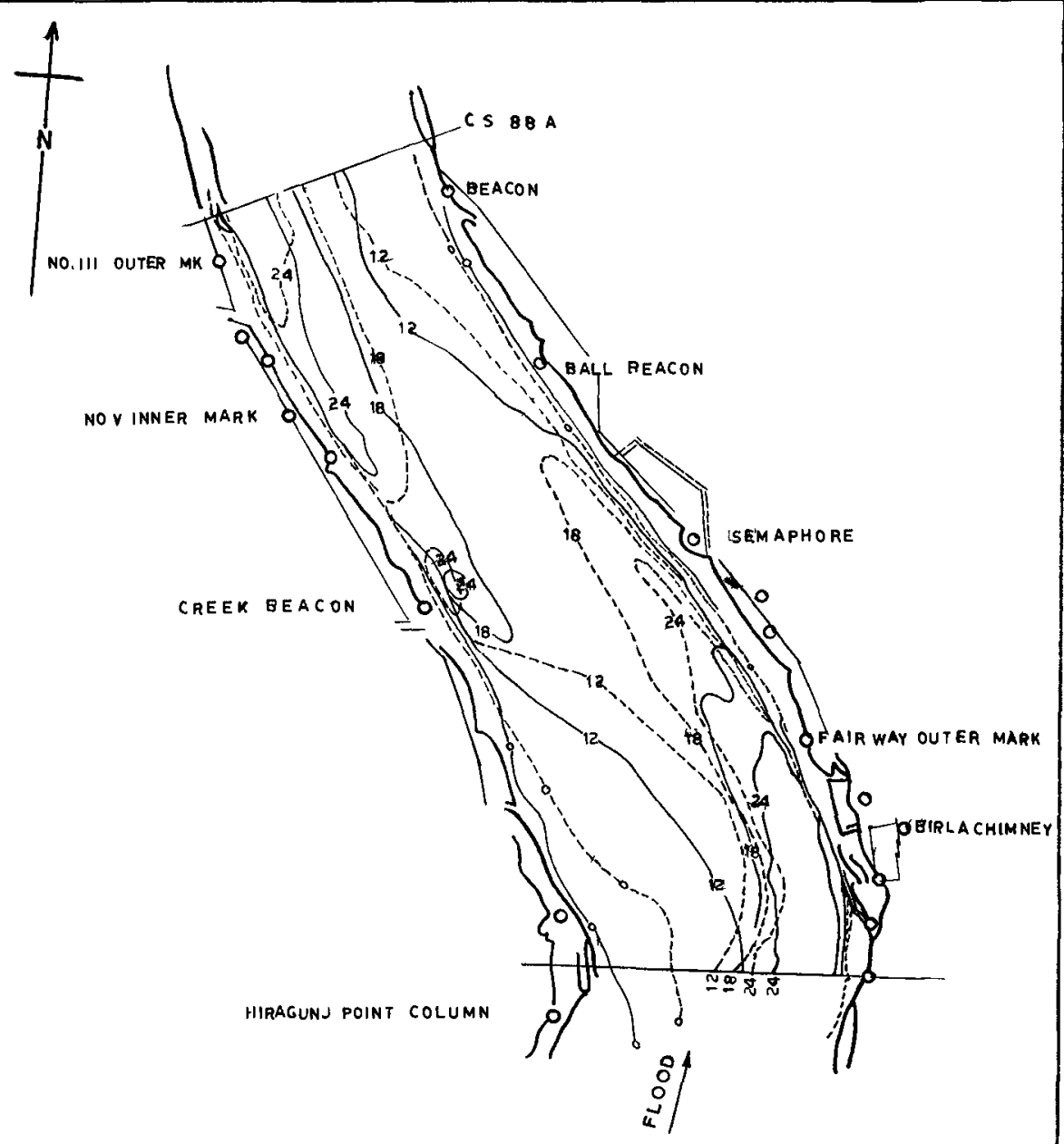

FIG.7

REFERENCE $~-$

RIVER HOOGHLY

-... MAY-JUNE 1957

NOV-DEC 1957

POST \& PREFRESHET

CHANNEL CONDITIONS

AT MOYAPUR BAR 

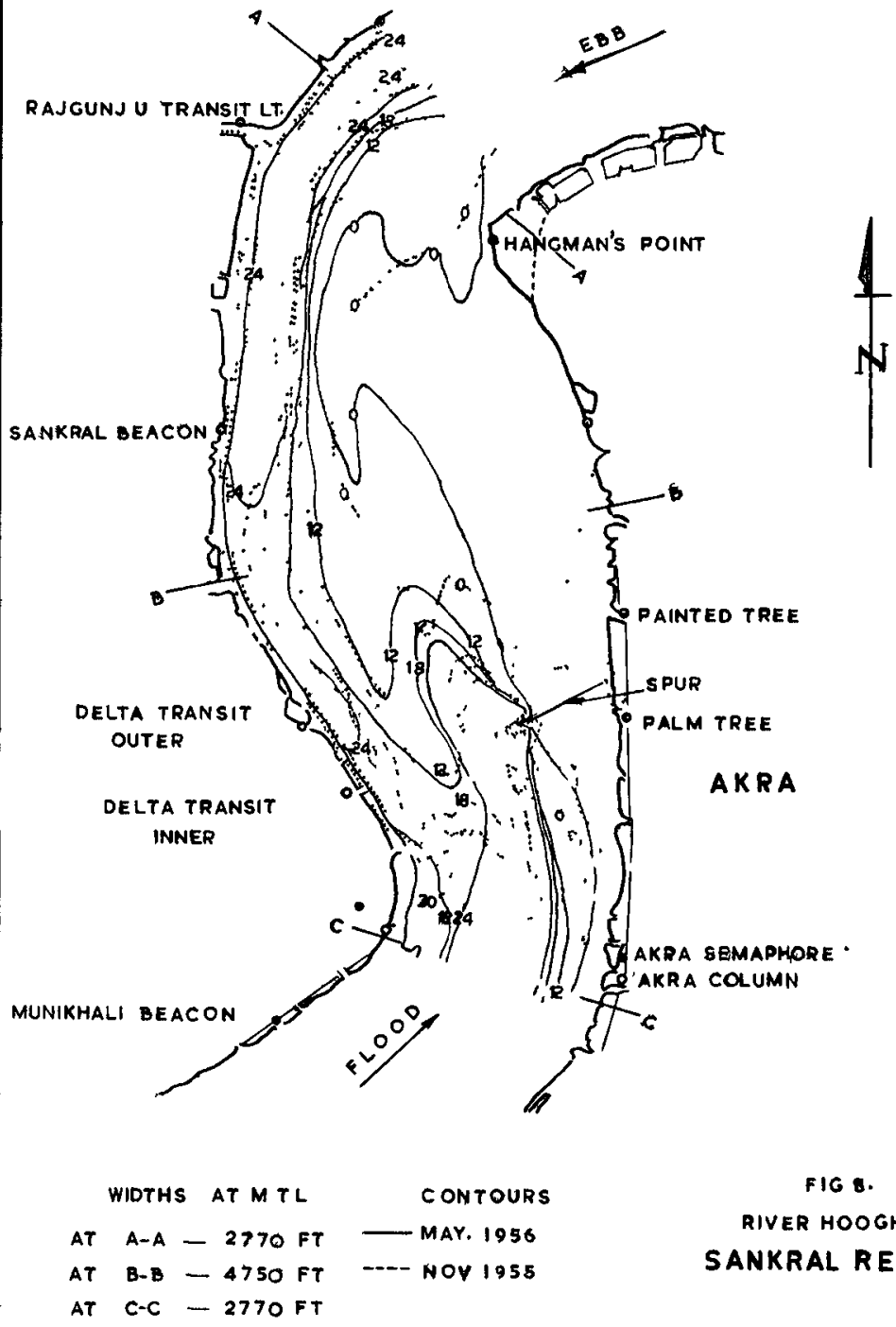

FIG 8.

RIVER HOOGHLY

SANKRAL REACH 


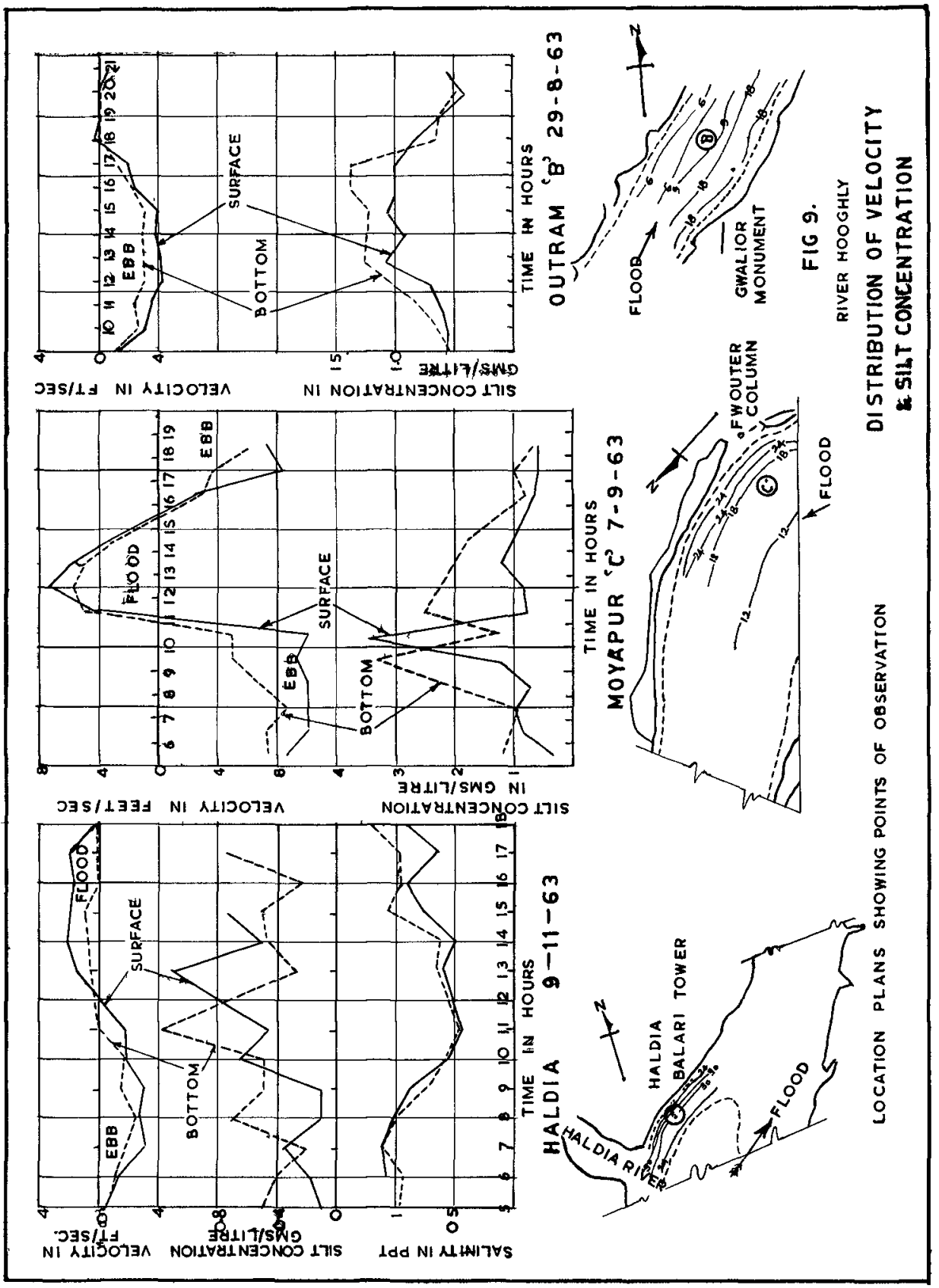




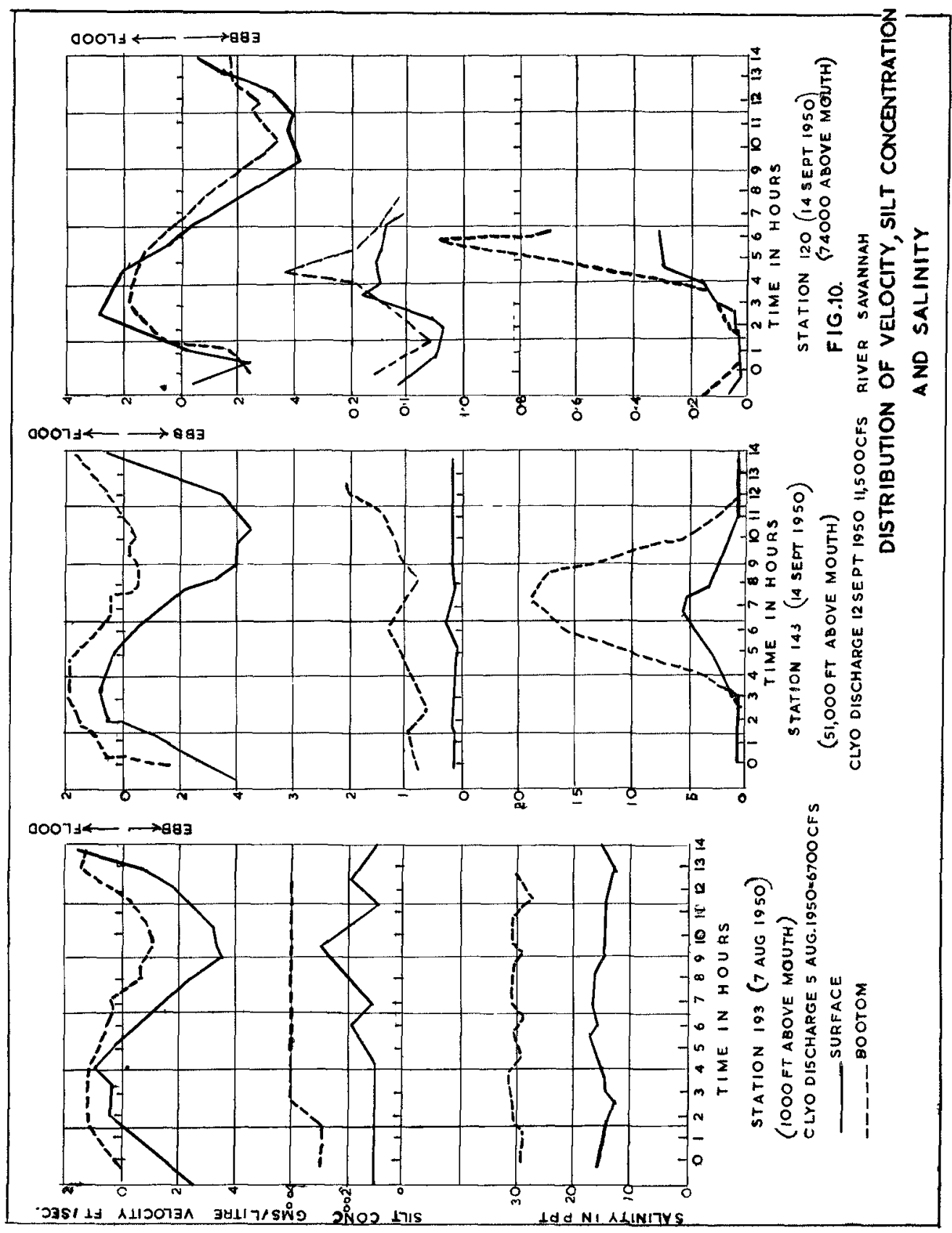




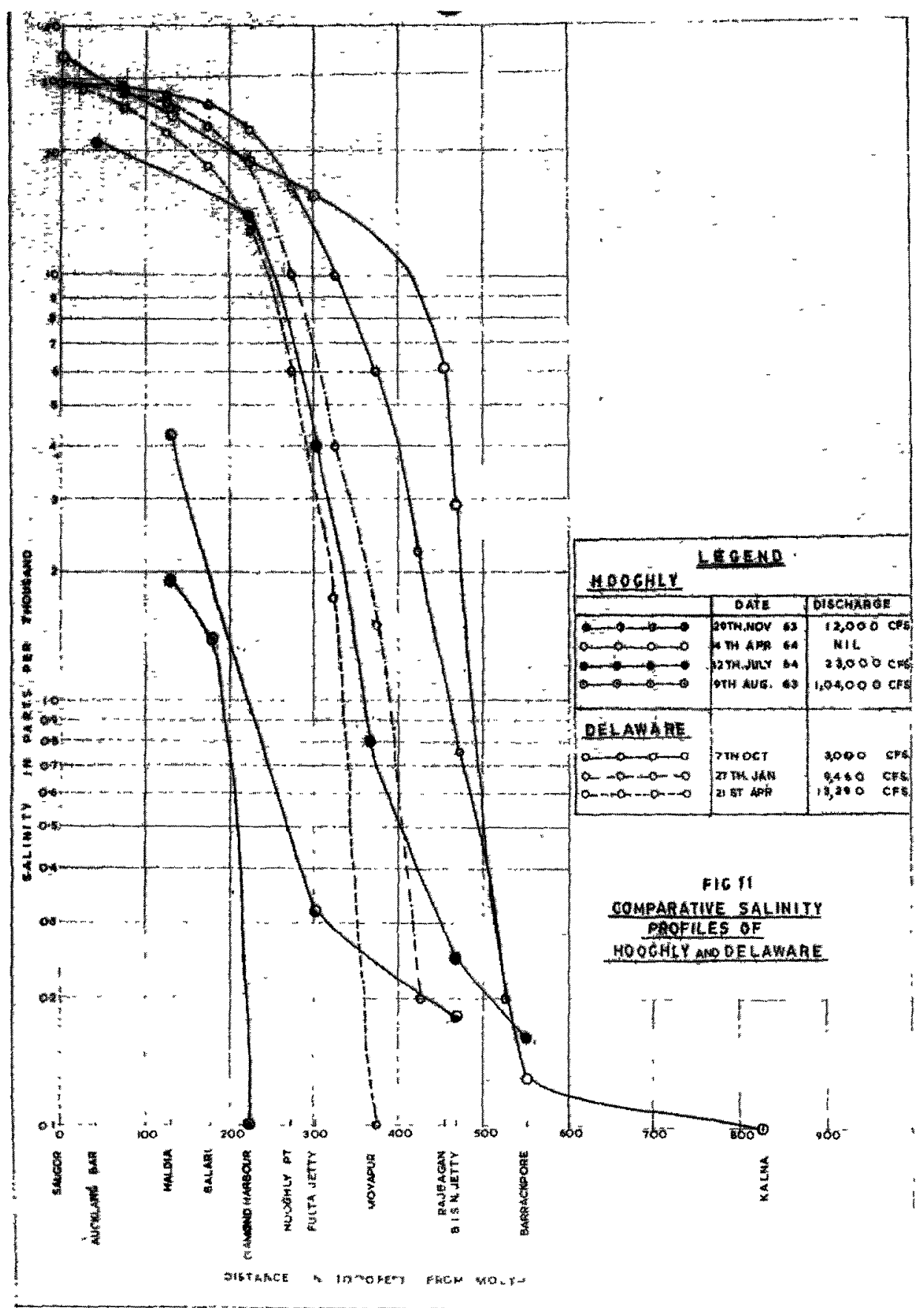




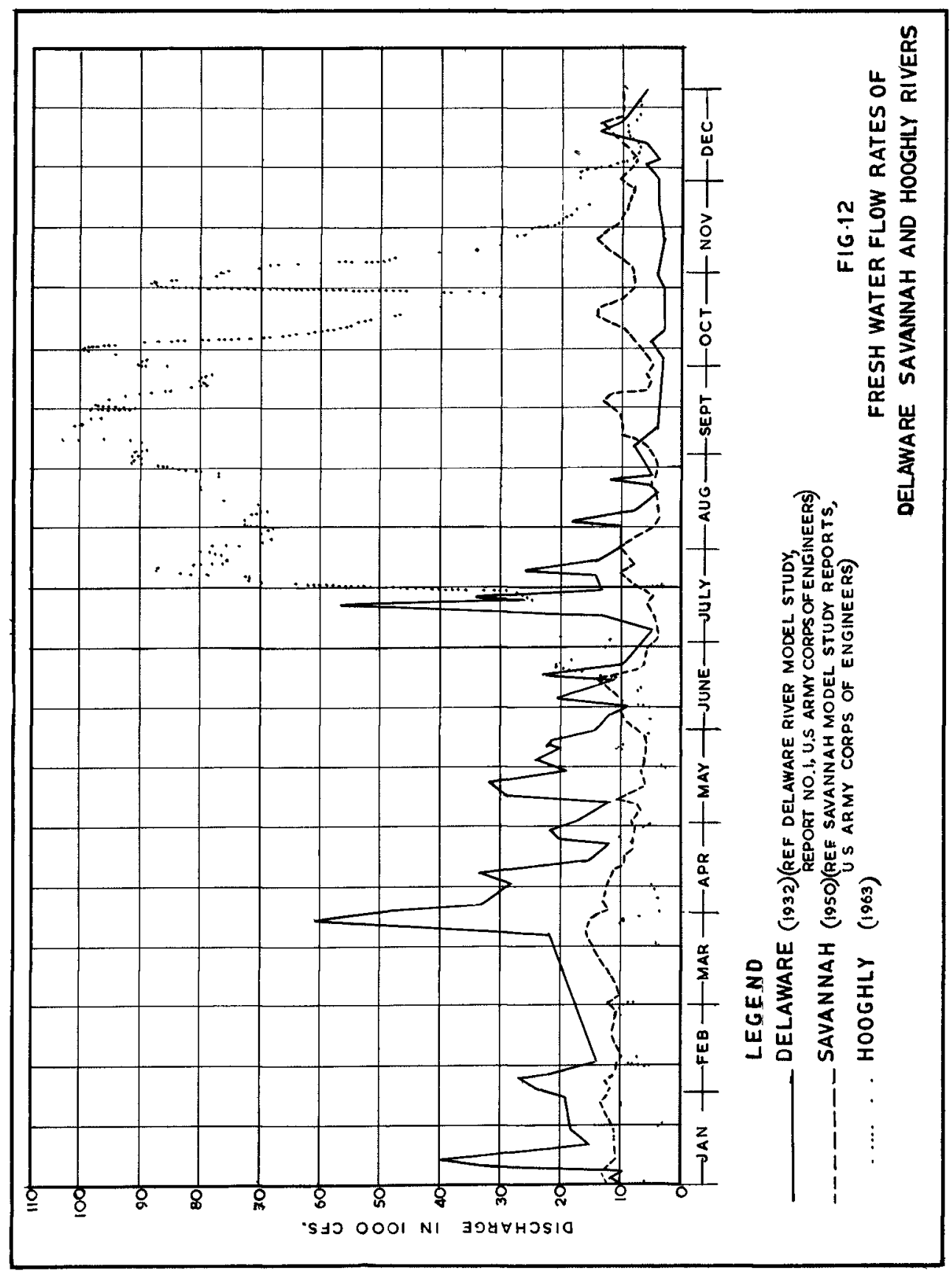

